\title{
Characterisation of and polysaccharide production by amoxycillin-resistant streptococci
}

\author{
P. D. MARSH, AILEEN A. WEST and C. W. KEEVIL \\ Bacterial Metabolism Research Laboratory, PHLS Centre for Applied Microbiology and Research, Porton Down, \\ Salisbury, Wiltshire SP4 QJG
}

\begin{abstract}
Summary. Small numbers of bacteria capable of growing on agar supplemented with amoxycillin $40 \mathrm{mg} / \mathrm{L}$ were isolated from the saliva of 9 out of 20 adult volunteers in a previous study. All the bacteria were identified as Streptococcus sanguis although no strains produced dextran in conventional tests. However, using a specific assay, all the antibiotic-resistant strains were found to secrete glucosyltransferases (GTF), the enzymes that synthesise these extracellular polysaccharides; the production of GTF$\mathrm{S}$, the enzyme that synthesises dextran, was $22-43 \%$ less than that of an antibioticsensitive control strain. Enzyme production by both antibiotic-resistant and sensitive bacteria was markedly inhibited by dextran primer. The amoxycillin-resistant bacteria were resistant to other penicillins; their resistance to erythromycin was variable but they were uniformly sensitive to cephalothin and clindamycin. As dextran production has been proposed as a key factor in the colonisation of damaged heart valves by bacteria such as $S$. sanguis, these highly resistant bacteria may not pose a threat to the susceptible individual.
\end{abstract}

\section{Introduction}

In a recent study of the effect on the oral flora of adult volunteers of repeated high-dose prophylaxis with amoxycillin, several antibiotic-resistant streptococci were isolated from saliva (Woodman et al., 1985). Of particular significance were the low numbers of streptococci isolated from 9 out of 20 subjects before prophylaxis that were able to grow on media supplemented with amoxycillin $40 \mathrm{mg} / \mathrm{L}$. This concentration corresponds to the peak serum levels of the antibiotic and, consequently, these organisms could pose a threat to patients at risk of infective endocarditis. In a similar study of antibiotic prophylaxis, Southall et al. (1983) reported that all 17 of their amoxycillin-resistant streptococci were dextran-negative Streptococcus sanguis. Although dextran-negative $S$. sanguis strains have been described (Price et al., 1986), most studies report that an overwhelming majority of strains produce extracellular polysaccharides from sucrose. Some of the highly amoxycillin-resistant streptococci from our recent study (Woodman et al., 1985) have now been identified. These strains were also unusual in that they consistently failed to produce dextran (glucan) during growth in the presence of

Received 10 Nov. 1986; revised version accepted 10 Jan. 1987. sucrose although they were able to secrete low concentrations of glucosyltransferases, the enzymes responsible for polysaccharide production.

\section{Materials and methods}

\section{Samples and subjects}

Stimulated whole saliva was collected from 20 healthy adult volunteers before their participation in a study of the effect of repeated high-dose prophylaxis with amoxycillin on the normal oral flora (Woodman et al., 1985).

\section{Bacteriology}

The bacteria present in saliva were dispersed by vortex mixing, serially diluted in nutrient broth and samples were plated on Mitis-Salivarius (MS) Agar (Oxoid) containing amoxycillin $40 \mathrm{mg} / \mathrm{L}$ to enable streptococci resistant to peak serum levels of the antibiotic to be enumerated (Woodman et al., 1985). All plates were incubated anaerobically for $72 \mathrm{~h}$ at $37^{\circ} \mathrm{C}$ in an atmosphere of $\mathrm{CO}_{2} 10 \%$ in $\mathrm{H}_{2}$. Bacteria were confirmed as streptococci on the basis of their colonial morphology, their appearance in gram-stained smears and their negative reaction in a catalase test; they were freeze-dried for subsequent identification by the criteria of Hardie and Bowden (1976) and by the commercially-available API 20 Strep System, (API, Basingstoke). Production of 
extracellular polysaccharide from sucrose was assessed by colonial texture on sucrose-containing agar, and by the production of a white precipitate after the addition of 1.2 volumes of ethanol to $5 \mathrm{ml}$ of culture filtrates (Hehre and Neill, 1946).

\section{Glucosyltransferase (GTF; EC 2.4.1.5) and fructosyltransferase (FTF; EC 2.4.1.10) activity}

Amoxycillin-resistant strains were grown in batch culture in a complex medium (LHP) containing potassium salts and supplemented with glucose $1 \% \mathrm{w} / \mathrm{v}$ at a constant $p \mathrm{H} 7.0$ by the automatic addition of $2 \mathrm{M} \mathrm{KOH}$ (Keevil $e t$ al., 1984). The bacteria were grown until late log phase and the enzymes that synthesise glucans and fructans from sucrose were assayed in culture supernates in the presence and absence of dextran primers $(60 \mu \mathrm{g} / \mathrm{ml}$, final concentration) by the method of Keevil et al. (1984). The enzymes that produce insoluble glucan (mutan) and insoluble fructan are GTF-I and FTF-I, respectively; activities were expressed as the amounts $(\mu \mathrm{g})$ of insoluble glucan or fructan that were polymerised from sucrose (/ml of culture supernate)/h. Similarly, soluble glucan (dextran) and soluble fructan are produced by the enzymes GTF-S and FTF-S, respectively; activities were also expressed as the amounts $(\mu \mathrm{g})$ of ethanol-precipitable glucan (dextran) or fructan that were polymerised from sucrose $(/ \mathrm{ml}$ culture supernate)/h.

\section{Antibiotic sensitivity patterns}

The minimum inhibitory concentrations (MIC) of several antibiotics for the strains were determined in multiwell polystyrene plates containing appropriate concentrations of dried, stabilised antibiotics arranged to give two-fold dilutions after addition of nutrient broth (Sensititre ${ }^{\circledR}$; Gibco Ltd, Paisley, Scotland). After incubation at $37^{\circ} \mathrm{C}$ for $24-48 \mathrm{~h}$, bacterial growth could be seen as a button of cells in the bottoms of wells.

\section{Results}

Low numbers of streptococci able to grow on agar supplemented with amoxycillin $40 \mathrm{mg} / \mathrm{L}$ were isolated from the saliva of 9 out of 20 volunteers. The mean viable count of these resistant bacteria was low $(116 \mathrm{cfu} / \mathrm{ml})$ but the range between individuals was wide $\left(0-2 \cdot 4 \times 10^{3} \mathrm{cfu} / \mathrm{ml}\right)$. In all subjects these highly-resistant bacteria represented $<0 \cdot 1 \%$ of the total cultivable flora.

Some of these highly-resistant bacteria died when freeze-dried. All of the remaining highly-resistant streptococci, when passed through the two established typing schemes, were identified as $S$. sanguis although none synthesised extracellular polysaccharides from sucrose. In the tests recommended by Hardie and Bowden (1976), all strains failed to ferment mannitol and sorbitol, or to produce acetoin from glucose, but they all liberated ammonia from arginine, hydrolysed aesculin and produced hydrogen peroxide. Similarly, using the API-20 Strep galleries, the only positive reactions were hydrolysis of aesculin, production of leucine arylamidase and arginine dehydrolase, and fermentation of lactose and starch. Colonies of the antibiotic-resistant strains were soft and non-adherent on sucrose-agar whereas a control culture-collection strain had a hard texture and could be detached from the agar surface only with great difficulty. Unlike the antibiotic-sensitive control strain, our highly-resistant streptococci did not produce ethanol-precipitable polysaccharide when grown in sucrose broth. However, when assays for the enzymes responsible for synthesising these polysaccharides were performed on culture supernates, low activities of GTF-S and GTF-I were detected (table I). The levels of GTF-S produced by the amoxycillinresistant strains were only $23-43 \%$ of that of an antibiotic-sensitive type-culture-collection strain (NCTC 7865) grown in identical conditions; the production of GTF-I was relatively similar and low in all the $S$. sanguis strains tested. The presence of low-molecular-weight dextran primer was markedly inhibitory to GTF-S secretion by all strains, but particularly by the antibiotic-resistant bacteria.

Table I. Extracellular glucosyltransferase (GTF) and fructosyltransferase (FTF) production by amoxycillinresistant oral streptococci

\begin{tabular}{|c|c|c|c|c|c|}
\hline \multirow[b]{2}{*}{ Strain no. } & \multirow{2}{*}{$\begin{array}{c}\text { Primer } \\
\text { present } \\
\text { or absent }\end{array}$} & \multicolumn{4}{|c|}{$\begin{array}{l}\text { Transferase activity } \\
(\mu \mathrm{g} / \mathrm{ml} / \mathrm{h} ; \pm \mathrm{SD})^{*} \\
\text { detected as }\end{array}$} \\
\hline & & GTF-S & GTF-I & FTF-S & FTF-I \\
\hline \multirow[t]{2}{*}{247} & - & $164 \pm 30$ & $22 \pm 24$ & 0 & 0 \\
\hline & + & $\overline{0}$ & $16 \pm 27$ & 0 & 0 \\
\hline \multirow[t]{2}{*}{254} & - & $168 \pm 41$ & $10 \pm 5$ & $5 \pm 6$ & 0 \\
\hline & + & $36 \pm 26$ & 0 & $\frac{1}{0}$ & 0 \\
\hline \multirow[t]{2}{*}{297} & - & $185 \pm 49$ & $26 \pm 8$ & 0 & 0 \\
\hline & + & $50 \pm 20$ & $3 \pm 7$ & 0 & 0 \\
\hline \multirow[t]{2}{*}{151} & - & $228 \pm 30$ & $12 \pm 5$ & 0 & 0 \\
\hline & + & $155 \pm 23$ & $2 \pm 2$ & 0 & 0 \\
\hline \multirow[t]{2}{*}{195} & - & $117 \pm 25$ & $25 \pm 6$ & 0 & 0 \\
\hline & + & $93 \pm 8$ & $17 \pm 5$ & 0 & 0 \\
\hline \multicolumn{6}{|l|}{ NCTC } \\
\hline \multirow[t]{2}{*}{$7865 \dagger$} & - & $530 \pm 40$ & $26 \pm 7$ & $90 \pm 15$ & $5 \pm 6$ \\
\hline & + & $350 \pm 23$ & $10 \pm 5$ & $40 \pm 7$ & $5 \pm 6$ \\
\hline
\end{tabular}

* Activities are expressed as the mean \pm SD of between 3-5 determinations on cultures grown on different days.

† This strain is sensitive to amoxycillin and is included as a control. 
Strain 247 produced no soluble glucan in the presence of primer and glucan production by strain 254 was inhibited by nearly $80 \%$. None of the amoxycillin-resistant strains produced FTF-I and only one, strain 254, secreted FTF-S (table I).

The MIC of amoxycillin for the streptococci isolated on agar supplemented with amoxycillin $40 \mathrm{mg} / \mathrm{L}$, fell on sub-culture although the MIC of amoxycillin for several strains exceeded $10 \mathrm{mg} / \mathrm{L}$. By use of a proprietary test system, these strains were found to be moderately resistant to a range of other penicillins and variable in their resistance to erythromycin, but were uniformly sensitive to cephalothin and clindamycin (table II).

\section{Discussion}

Transient bacteraemia commonly follows several routine dental procedures. Consequently, patients at risk of infective endocarditis receive antibiotic prophylaxis before such treatment (Cawson, 1981). A common misconception is that streptococci, the bacteria most frequently isolated from patients with infective endocarditis (Lowes et al., 1980; Moulsdale et al., 1980), are always sensitive to the penicillins. Several studies have reported the widespread carriage of small numbers of penicillinresistant streptococci in the oral cavity of healthy subjects (Drucker and Jolly, 1971; Sukchotiratana et al., 1975; Phillips et al., 1976; Southall et al., 1983; Woodman et al., 1985). Significantly, the numbers of these resistant bacteria are greater in people exposed more frequently to antibiotics, such as those at risk of infective endocarditis (Phillips $e t$ al., 1976; Shanson and Namayak, 1982), or in those who have recently received prophylactic cover or a short course of antibiotic treatment (Southall et al.,
1983; Harrison et al., 1985a; Woodman et al., 1985). Erythromycin is recommended as an alternative antibiotic when there is concern that penicillin-resistant bacteria may have been selected. The amoxycillin-resistant bacteria in our studies showed some resistance to erythromycin but were uniformly sensitive to clindamycin, another alternative antibiotic.

These antibiotic-resistant streptococci have not been identified routinely. However, Southall et al. (1983) reported that the amoxycillin-resistant streptococci isolated in their study were similar to $S$. sanguis except that all 17 isolates from 11 volunteers were atypical in that they did not produce dextran. Dextran-negative erythromycin-resistant strains of $S$. sanguis have also been described recently (Harrison et al., 1985b). This is surprising because although dextran-negative $S$. sanguis have been reported, they are relatively uncommon and most strains characteristically synthesise polysaccharides (Price et al., 1986). In our previous study, bacteria were isolated that could grow on agar supplemented with amoxycillin $40 \mathrm{mg} / \mathrm{L}$ and, as this concentration corresponds to the peak serum levels of the antibiotic, they were considered to pose a potentially significant threat to the patient. These highly-resistant bacteria were identified as dextran-negative $S$. sanguis on the basis of conventional criteria including colonial texture on sucrose agar and precipitation of supernates with ethanol. However, using a specific assay, all strains were found to be capable of secreting glucosyltransferases that synthesise such extracellular glucans, although the activities of GTF-S, the enzyme responsible for dextran production, was lower in culture supernates of resistant strains than in that of an antibiotic-sensitive strain included as a control. This apparent paradox might be explained

Table II. Antibiotic sensitivity profile of amoxycillin-resistant streptococci

\begin{tabular}{|c|c|c|c|c|c|c|c|c|c|c|c|}
\hline \multirow[b]{2}{*}{ Strain no. } & \multicolumn{11}{|c|}{ Minimum Inhibitory Concentration (mg/L) } \\
\hline & Pen G & Amp & Oxa & Gent & Amik & Tet & Chlor & Eryth & Ceph & Clind & Co-trim \\
\hline 151 & 4 & $>16$ & $>16$ & 1 & 8 & 2 & 2 & $0 \cdot 5$ & $<0.25$ & $<0 \cdot 12$ & 4 \\
\hline 195 & 2 & 8 & 4 & 1 & 1 & 0.5 & 1 & $<0 \cdot 25$ & $<0.25$ & $<0 \cdot 12$ & 4 \\
\hline 247 & $>8$ & $>16$ & $>16$ & 2 & 16 & 2 & 2 & 1 & 0.25 & $<0.12$ & 4 \\
\hline 254 & 4 & 8 & 8 & 0.5 & 4 & 2 & 1 & 0.5 & $<0.25$ & $<0.12$ & 4 \\
\hline 297 & $>8$ & $>16$ & $>16$ & 1 & 4 & 8 & 1 & 2 & $<0.25$ & $<0.12$ & $>8$ \\
\hline NCTC $7865^{*}$ & $<0.06$ & $<0.12$ & 0.5 & 2 & 8 & 0.5 & 4 & 0.25 & $<0.25$ & $0 \cdot 25$ & 4 \\
\hline
\end{tabular}

Pen G, penicillin G; Amp, ampicillin; Oxa, oxacillin; Gent, gentamicin; Amik, amikacin; Tet, tetracycline; Chlor, chloramphenicol; Eryth, erythromycin; Ceph, cephalothin; Clin, clindamycin; Co-trim, co-trimoxazole.

* $S$. sanguis NCTC 7865 is an antibiotic sensitive strain included as a control. 
by the finding that, unlike $S$. mutans (Fukui et al., 1982), dextran synthesis by $S$. sanguis (Keevil et al., 1984), and particularly by our antibiotic-resistant strains, is markedly inhibited by low-molecularweight dextran primers. Sucrose can act as both substrate and inducer to some enzymes; therefore, the relatively high concentrations of this sugar in the TYC agar plates and in the broth cultures might have inhibited polysaccharide production.

The adherence of streptococci to damaged heart valves in vitro (Ramirez-Ronda, 1978) and to a platelet-fibrin matrix (Scheld et al., 1978) has been shown to be enhanced by the ability of cells to synthesise glucans (Mills et al., 1984). Similarly, pre-exposure of bacteria or valve-leaflets to preformed dextrans of low molecular weight can interfere with this attachment (Ramirez-Ronda, 1980) confirming the important role of extracellular polysaccharides in the pathogenicity of certain oral

\section{REFERENCES}

Cawson R A 1981 Infective endocarditis as a complication of dental treatment. British Dental Journal 151 : 409-414.

Drucker D B, Jolly M 1971 Sensitivity of oral micro-organisms to antibiotics. British Dental Journal $131: 442-444$.

Fukui K, Moriyama T, Miyake Y, Mizutani K, Tanaka O 1982 Purification and properties of glucosyltransferase responsible for water-insoluble glucan synthesis from Streptococcus mutans. Infection and Immunity 37: 1-9.

Harrison G A J, Rubin M P, Davies R M, Speller D C E $1985 a$ Resistance in oral streptococci after repetition of a singledose amoxycillin prophylactic regimen. Journal of Antimicrobial Chemotherapy 15:501-503.

Harrison G A J, Stross W P, Rubin M P, Davies R M, Speller D C E $1985 b$ Resistance in oral streptococci after repeated three-dose erythromycin prophylaxis. Journal of Antimicrobial Chemotherapy 15:471-479.

Hardie J M, Bowden G H 1976 Physiological classification of oral viridans streptococci. Journal of Dental Research 55: A166-176.

Hehre E J, Neill J M 1946 Formation of serologically reactive dextrans by streptococci from subacute bacterial endocarditis. Journal of Experimental Medicine 83: 147-162.

Keevil C W, West A A, Bourne N, Marsh P D 1984 Inhibition of the synthesis and secretion of extracellular glucosyl- and fructosyltransferase in Streptococcus sanguis by sodium ions. Journal of General Microbiology 130:77-82.

Lowes J A et al. 198010 years of infective endocarditis at St Bartholomew's Hospital: analysis of clinical features and treatment in relation to prognosis and mortality. Lancet 1:133-136.

Mills J, Pulliam L, Dall L, Marzouk J, Wilson W, Costerton J W 1984 Exopolysaccharide production by viridans streptococci in experimental endocarditis. Infection and Immunity 43:359-367.

Moulsdale M T, Eykyn S J, Phillips I 1980 Infective endocarditis 1970-79. A study of culture positive cases in St Thomas's Hospital. Quarterly Journal of Medicine 49:315-328. streptococci, and particularly $S$. sanguis. Thus, although these amoxycillin-resistant bacteria possess glucosyltransferases but appear to be unable to synthesise glucans under certain environmental conditions, they may not be able to attach to a damaged endocardium. If this is confirmed, these highly-resistant bacteria would not be considered a threat to a susceptible patient nor would their selection following repeated antibiotic administration invalidate prophylaxis (Southall et al., 1983; Harrison et al., 1985a; Woodman et al., 1985). We are continuing to investigate these possibilities in in-vitro attachment models and in in-vivo studies of pathogenicity in an animal endocarditis model.

We thank Mr A. Featherstone for his skilled technical assistance during the early stages of this study. AAW was a recipient of a grant from the Medical Research Council of Great Britain (G 8310210 SB).

Phillips I, Warren C, Harrison J M, Sharples P, Ball L C, Parker M T 1976 Antibiotic susceptibilities of streptococci from the mouth and blood of patients treated with penicillin or lincomycin and clindamycin. Journal of Medical Microbiology $9:$ 393-404.

Price T, French G L, Talsania H, Phillips I 1986 Differentiation of Streptococcus sanguis and $S$. mitior by whole-cell rhamnose content and possession of arginine dihydrolase. Journal of Medical Microbiology 21 : 189-197.

Ramirez-Ronda C H 1978 Adherence of glucan-positive and glucan-negative streptococcal strains to normal and damaged heart valves. Journal of Clinical Investigation 62:805814.

Ramirez-Ronda C H 1980 Effects of molecular weight of dextran on the adherence of Streptococcus sanguis to damaged heart valves. Infection and Immunity 29:1-7.

Scheld W M, Valone J A, Sande M A 1978 Bacterial adherence in the pathogenesis of endocarditis. Interaction of bacterial dextran, platelets, and fibrin. Journal of Clinical Investigation 61 : $1394-1404$.

Shanson D C, Namayak S 1982 Viridans streptococci with reduced bactericidal susceptibility to penicillin from patients with endocarditis: susceptibilities to erythromycin, rifampicin, vancomycin and aminoglycosides. In: Periti $P$, Grassi G G (eds) Current chemotherapy and immunotherapy. American Society of Microbiology, Washington D.C., pp 311-313.

Southall P J, Mahy N J, Davies R M, Speller D C E 1983 Resistance in oral streptococci after repeated two-dose amoxycillin prophylaxis. Journal of Antimicrobial Chemotherapy 12: 141-146.

Sukchotiratana M, Linton A H, Fletcher J P 1975 Antibiotics and the oral streptococci of man. Journal of Applied Bacteriology 38: 277-294.

Woodman A J, Vidic J, Newman H N, Marsh P D 1985 Effect of repeated high dose prophylaxis with amoxycillin on the resident oral flora of adult volunteers. Journal of Medical Microbiology 19: 15-23. 